\title{
Post-Keynesian stock-flow models after the subprime crisis: the need for micro-foundations
}

\author{
Photis Lysandrou \\ Research Fellow, Political Economy Research Centre, City University (CITYPERC), London, UK
}

\begin{abstract}
The subprime crisis exposed a flaw in post-Keynesian stock-flow models, namely their concession to mainstream macroeconomic theory that financial markets obey a price-clearing rule. Two reasons lie behind this concession. The first is the assumption that investors give priority to the price dimension of securities and only secondary importance to their quantity dimension. This paper argues that following recent structural changes in domestic economies the securities markets are now dominated by investors who give co-priority to the price and quantity dimensions of securities, for which reason these markets now operate to the same demand-led quantity adjustment process as do all other markets. The second and more fundamental reason is that post-Keynesian stock-flow models lack a micro-foundational unit of analysis from which can be derived an overarching methodological framework that is not only externally realistic but also internally coherent. This paper argues that the unit of analysis that best fits this purpose is the 'commodity', a term that will be used both exclusively, to denote only those entities that are priced to a market standard, and inclusively, to denote not only the outcomes of human activities but also the capacities for activity that are subject to pricing standards.
\end{abstract}

Keywords: post-Keynesian stock-flow models, subprime crisis, micro-foundations, commodity

JEL codes: $E 12, G 01$

\section{INTRODUCTION}

One of the by-products of major capitalist crises is that they can help expose certain weaknesses in the main economic theories of the day. The recent Great Financial Crisis is no exception. Post-Keynesian theorists generally agree that this crisis has severely damaged the credibility of mainstream macro models by exposing the myths of self-stabilising markets and self-regulating institutions. ${ }^{1}$ However, the crisis has also revealed a flaw in post-Keynesian stock-flow models that are now a staple of the post-Keynesian economic paradigm, namely their concession to mainstream theory that financial markets obey a price-clearing rule. This conclusion is prompted by evidence that a major factor behind the rapid expansion of the US market for collateralised debt obligations (CDOs), the subprime-backed securities that triggered the financial crisis, was the futile attempt on

1. Indeed, the crisis has also damaged the credibility of current mainstream macro models, even in the eyes of those of who helped to construct or promote them. See, for example, Kocherlakota (2010) and Coeure (2012).

Received 27 August 2013, accepted 15 December 2013 
the part of the US banks to satisfy the insatiable demand for yield spilling over from the other US debt markets. This evidence is clearly embarrassing for post-Keynesian stockflow models because in conceding that the financial markets always clear through price adjustments they clearly cannot admit the possibility of excess demand pressure spilling over from one financial market to another.

This paper attempts to correct this flaw by addressing what are considered to be the two major reasons behind it. The first is the assumption that agents give primacy to the price dimension of financial securities - their ability to generate an expected rate of return as determined by the movements in their market prices from one period to the next and only secondary importance to the quantity dimension of securities - their ability to hold a certain amount of value from one period to the next. The paper will argue that, following recent structural changes in contemporary capitalist economies, the securities markets are now dominated by agents who give co-primacy to the price and quantity dimensions of securities, for which reason these markets now obey the same adjustment rules as apply in the labour and product markets. The other, more fundamental reason for the flaw in post-Keynesian stock-flow models is the absence of micro-foundations. To make them realistic from the very outset, the models begin with a description of all the linkages between the real and financial sectors of an economy. However, the problem with this highly aggregative point of departure is that the differences between these sectors are foregrounded at the expense of what they have in common, an imbalance that then results in a loss of coherence in that they appear to operate to different logics. PostKeynesian stock-flow models must certainly be realistic, but if they are also to be logically coherent they must begin with a micro-foundational unit of analysis upon which can be built an overarching framework that satisfies both criteria. This paper will argue that the unit of analysis that best fits this purpose is Marx's concept of 'commodity' as developed in Capital (1867 [1961]), a concept that is used both exclusively, to denote only those entities that are priced according to a market standard, and inclusively, to denote not only the outcomes of human activity but also the capacities for activity that are subject to pricing standards.

The paper is structured as follows. Section 2 briefly describes the standard postKeynesian stock-flow model and explains the reasons for its dichotomised approach to market clearing in the real and financial markets. Section 3 explains why this dichotomised approach is now an anachronism. Section 4 discusses the methodological advantages of commodity reductionism. Section 5 discusses the policy-relevant advantages of commodity reductionism. Section 6 concludes.

\section{THE STANDARD POST-KEYNESIAN STOCK-FLOW MODEL}

Post-Keynesian stock-flow models, of which we take the Godley-Lavoie (henceforth G-L) versions presented in their seminal text of 2007 (second edition, 2012) as archetypal, attempt to provide a complete representation of all the interlocking real and financial relations that characterise a modern capitalist economy. This representation is given in two dimensions: an accounting dimension that specifies the systemic constraints on all economic activities; and a behavioural dimension that specifies the motivations behind those activities. In G-L, the accounting relations are formally captured in three sets of matrices: a stock matrix; a transactions flow matrix; and a full integration matrix. The central flow matrix is illustrated in Table 1. The upper part of the matrix indicates the income and expenditure flows, while the lower part indicates the resulting changes in assets and liabilities. The summations to zero of the values in the horizontal rows manifest 


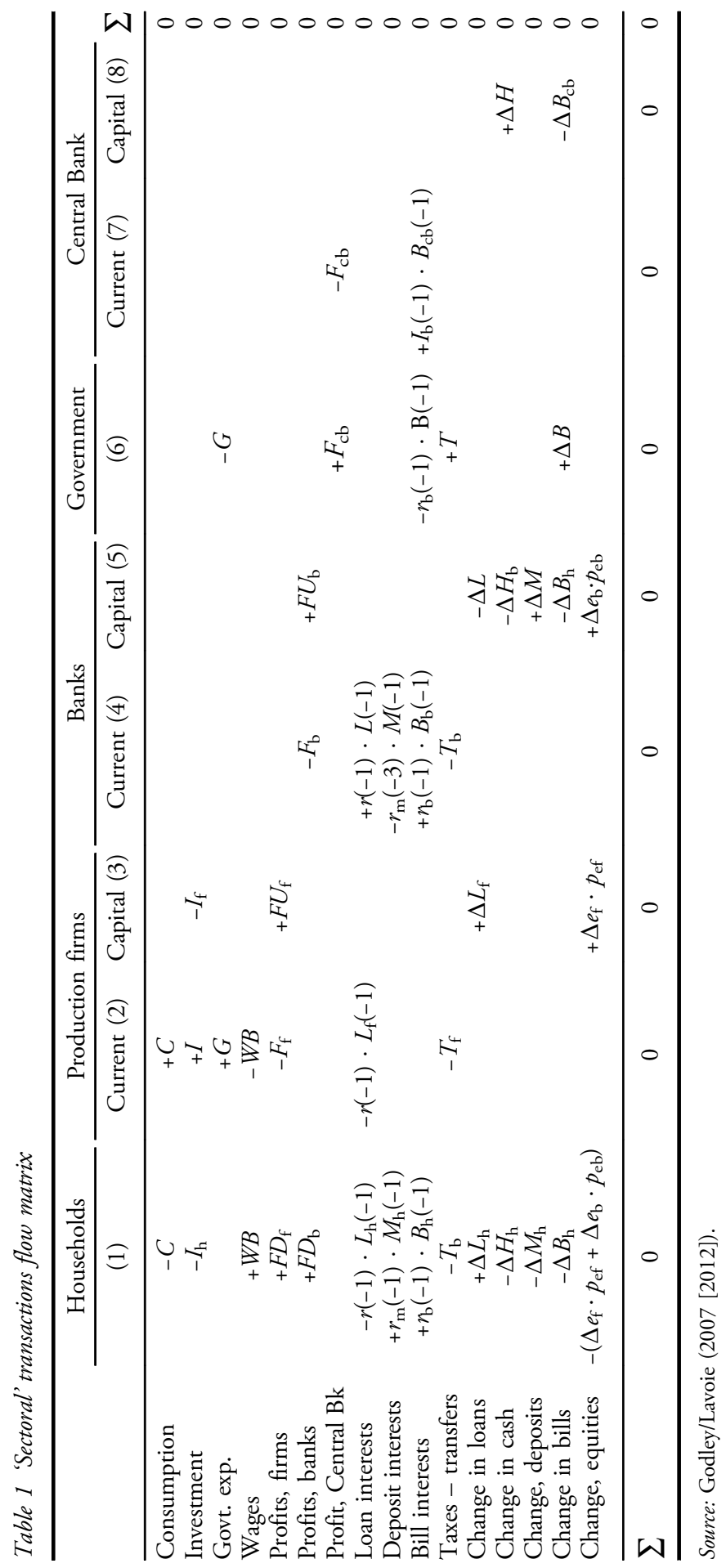


the interdependence between sectors - the fact that the use of funds by one sector, indicated by the negative values, corresponds to the source of funds in another sector, indicated by the positive values. The summations to zero of the values in the vertical columns manifest the budget constraints for each sector - the fact that the balances between expenditure and income flows generate counterpart changes in stocks of assets and liabilities. In sum, 'the accounts of the transaction flow matrix', to quote $\mathrm{G}-\mathrm{L}$, 'are comprehensive in the sense that everything comes from somewhere and everything goes somewhere ... With this framework, there are no black holes' (2007 [2012]: 38).

The behavioural relations are formally captured in equations. G-L present a series of behavioural models, each more complex and containing more equations than its predecessor, but the basic behavioural assumptions embedded in the equations remain the same. These differ from those of mainstream macro models in two essential respects, one as regards 'information' and the other as regards 'incentives'. Where mainstream models posit agents as perfectly rational, forward-looking individuals able to process all available information instantaneously and efficiently, the G-L models posit agents as reasonably rational individuals who make decisions based on expectations or predictions about an uncertain future; and where mainstream models posit agents as having as their single objective the maximisation of utility or profit, the G-L models posit decision-making less as a choice-maximising exercise than as a time-consuming process linked to the specific functions performed by different groups of agents. The upshot is that, as compared with mainstream macro models, the $\mathrm{G}-\mathrm{L}$ models have considerable strengths. However, the same comparison also serves to expose their major weakness, which is their concession to mainstream macro theory that the financial markets obey a price-based rather than a quantity-based clearing rule.

At the root of this concession is the differential treatment of real and financial entities that is a characteristic feature of all post-Keynesian macro theory. As concern real entities, post-Keynesians recognise that their physical, quantity dimension is as important in agents' decision-making process as is their price dimension: households not only look at the prices of goods but also at their material characteristics to check whether these fit in with their consumption needs before deciding on what quantities to buy, while firms not only look at the prices of material and human inputs but also at their physical or skill quality before deciding on what quantities to purchase for production purposes. It is this dual focus on the quantity and price dimensions of real entities, in addition to assumptions about imperfect information, uncertainty and time-consuming production, which explains why post-Keynesians posit market clearing in the product and labour markets on the basis of demand-led quantity adjustments. By contrast, in the case of financial entities such as debt and equity securities, it is only the 'price' dimension that is presumed to enter into the decision-making calculus; when households are in a position to save part of their income, the sole criterion for choosing between the different financial savings instruments available is a comparison of the expected rates of return, and when firms turn to external funding for investment purposes the sole criterion for choosing between the alternative forms of fund-raising is a comparison of the rates of return that have to be paid. Just as households and firms independently make saving and borrowing decisions based on price (rate of return) comparisons, so in turn prices constantly adjust to reconcile the aggregate saving and borrowing decisions. In sum, it is because the demands for, and supplies of, securities are merely a residual of price-based decisions made in the real markets that explains why $\mathrm{G}-\mathrm{L}$, in common with all post-Keynesians, see financial markets as the one exception where clearing is through prices (as they state, 'market clearing through prices does not usually occur except in financial markets' (2007 [2012]: 18)) and why they see equilibrium and not disequilibrium as the more characteristic end state of these 
markets (as Godley/Lavoie state in an earlier publication, 'with trivial exceptions, there are no equilibria (or disequilibria) outside financial markets' (2006: 2). ${ }^{2}$

This characterisation of financial markets as self-equilibrating through price adjustments appears to be sharply at odds with developments in the US in the period immediately prior to the subprime crisis. Among the most striking of these developments was the rapid expansion of the markets for asset-backed securities (ABSs) and for collateralised debt obligations (CDOs), the products that triggered the crisis. While post-Keynesian explanations of these developments differ in many important respects from mainstream explanations, they coincide with the latter on one crucial point, namely that the driving forces behind the growth of the ABS and CDO markets were ultimately to be found on the supply side of these markets, with the banks in particular being given primacy, while demand-side factors played a largely passive role. This interpretation of events simply does not square with their time-frame. The US ABS market has existed for over 4 decades, and yet of the $\$ 9$ trillion or so's worth of US ABS stocks outstanding at end 2006, over half (\$5.2) had been created in the preceding 4 years; in other words, during exactly the same period as the major US government and corporate bond markets were experiencing unusually low yields. ${ }^{3}$ Similarly, the US CDO market had first come into existence in the 1980s, and yet of the $\$ 2.6$ trillion or so worth of US CDOs outstanding at end 2006, over 95 per cent had been created in the preceding 4 years; in other words, during exactly the same period when not only the US government and corporate bond markets but also the US ABS market were experiencing unusually low yields. These close correlations between the downward trends in US bond yields between 2002 and 2006 and the rapid growth of the US ABS and CDO markets indicate that the main pressure on the US banking system to create these securities came from investors searching for yield. ${ }^{4}$ This demand-pull explanation of $\mathrm{ABS}$ and $\mathrm{CDO}$ growth certainly does not discount the importance of other contributory factors including 'the often emphasized regulatory and corporate governance weaknesses, misguided homeownership policies, and unscrupulous lenders', to quote Riccardo Caballero (2010: 5). Rather, again to quote the latter, it is to identify the fact that the importance of these factors lay mainly in determining the minimum resistance path for the safe-assets imbalance to release its energy' (ibid.: 5). In my view, there can be no better, or more eloquent, encapsulation of the circumstances surrounding US ABS and $\mathrm{CDO}$ growth in the immediate pre-crisis period. Equally, there can be no better encapsulation of the deficiencies in the post-Keynesian stock-flow models, for in holding fast to the premise that financial markets are automatically self-clearing they simply cannot accept the idea of a 'safe assets imbalance' that needs 'to release its energy'.

\section{THE ANACHRONISM OF THE DICHOTOMISED TREATMENT OF REAL AND FINANCIAL MARKETS}

What the pre-crisis developments in the US bond markets are telling us is that there now exists a significant group of investors in these markets for whom substantive adjustments

2. In chapter 5 of G-L (2007 [2012]), which deals with the government bond market, the authors point out that in this case bond supplies are typically adjusted so as to maintain stability in their price. However, this point does not fundamentally undermine the criticism advanced in this paper, as will be further explained in footnote 7 .

3. See Bernanke et al. (2011) and Lysandrou (2011).

4. For quantitative estimations of the impact of investor demand on US bond yields in the precrisis period, see Bandholz et al. (2009), Warnock/Warnock (2009), Goda/Lysandrou (2013) and Goda et al. (2013). 
in bond prices in response to shifts in aggregate demand and supply schedules represent less an equilibrating process than a disequilbrating one. Who are these investors? The answer is institutional investors, most notably pension and mutual funds and insurance companies. In the G-L models, these investors are not separated out from households, the assumption clearly being that as any difference between them can only be a difference of degree (professional asset managers have greater expertise) and not of kind (professional asset managers have basically the same investment objectives as amateur households), it can have no theoretical significance. In rentier models, institutional asset managers are distinguished from ordinary households that rely on wages to finance expenditures, but not from households that rely on rental incomes to finance spending. ${ }^{5}$ Here, once again, as the assumption is that any difference between professional rentiers and household rentiers is a difference of degree, not of kind, it makes no sense to separate out the former as a distinct group in its own right. The problem with these assumptions is their anachronism: while they had validity in the past when institutional asset management was for a long time a small cottage industry catering merely for the wealthy, they have now been rendered invalid by the recent transformation of asset management into a mass industry catering for the retirement and other welfare needs of large sections of the population. ${ }^{6}$

This development has opened up a fundamental divide between the investors of the present and the investors of the past. Whatever else may have separated the latter, what they all had in common was the fact that they never had cause to treat an asset portfolio as a product to be marketed to the public. By contrast, this is exactly how the institutional asset managers of today must treat portfolios if they are to accommodate the increased demands placed upon them while containing the costs of that accommodation. Rather than advise clients on how best to invest their money to achieve certain investment goals, asset managers now find it easier and cheaper to put on offer a wide array of standardised portfolios, each managed to a target riskreturn ratio, and then invite clients to choose the portfolio that suits their particular risk appetite.

It is this standardisation of the asset management function that explains why institutional investors now need to give as much importance to the quantity dimension of securities as to their price dimension, a fact that in turn explains why they need, more than was the case before, security prices to follow a stable rather than a volatile path. The logic is straightforward. Over any given period, a portfolio has to maintain a certain value capacity in which clients' monies are stored; as individual securities are the constituent elements of any portfolio, it follows that there needs to be stability in their prices if there is to be stability in their contribution to the portfolios' overall value storage capacity. Similarly, over any given period, a portfolio has to stay close to the target yield that funds the monies paid back to clients; as individual securities are the constituent elements of any portfolio, it follow that there needs to be stability in their prices if there is to be stability in their yield and hence in their contribution to the portfolios' overall yield profile. Price stability of securities requires that their aggregate demand and supply schedules constantly match: if aggregate supply exceeds aggregate demand, then supply quantity must be reduced or the demand increased if prices are not to fall; conversely, if aggregate demand exceeds aggregate supply, then demand quantity must be reduced or supply quantity increased in order to prevent a rise in prices. The upshot is that equilibrating adjustments in this context are quantity adjustments, not price adjustments; on the contrary, the latter will not only not maintain or restore equilibrium

5. For a stock-flow model that includes a rentier sector, see for example Van Treeck (2009).

6. This point is further developed in Grahl/Lysandrou (2006) and Lysandrou/Stoyanova (2007). 
but will also cause or accentuate disequilibrium. ${ }^{7}$ Thus, if security prices fall in the face of excess supplies, this reduces the size of their value storage capacity, while if security prices rise in the face of excess demand this will reduce their yields and thus the sums paid back to clients. It was precisely this latter development in the US bond markets after the end of the dot.com bubble in 2001 that became a serious enough problem as to require extraordinary measures to resolve it, measures that ultimately ended in disaster in mid-2007.

\section{THE METHODOLOGICAL ADVANTAGES OF COMMODITY REDUCTIONISM}

The second and more fundamental reason for the flaw in post-Keynesian stock-flow models is the absence of micro-foundations. The contrast with mainstream macro models on this issue is stark.

Mainstream theorists embrace methodological reductionism because they place greater emphasis on the internal consistency of models: ${ }^{8}$ by reducing an economic system to a representative choice-maximising agent, mainstream theorists can see across the system and identify what all its parts have in common; specifically, they can postulate the same price clearing for all markets.

Post-Keynesians, by contrast, resist methodological reductionism because they place greater emphasis on the external consistency of their models: they begin with a set of accounting matrices precisely in order to ensure that the behavioural assumptions of their models always touch base with the realities and constraints of a monetary production economy. However, the problem in taking a 'sectoral' transactions flow matrix as the overarching framework of the macro models is that the differences between the different parts of an economy are foregrounded at the expense of their similarities, an imbalance that then results in two different rules of market clearing: a quantity adjustment rule for the real markets and a price adjustment rule for the financial markets.

7. While Godley/Lavoie (2007 [2012]) argue that equity and corporate bond markets follow a price adjustment rule, they also point out in chapter 5 of their book that the government bond market usually follows a quantity adjustment rule. This is because the Treasury will typically vary government bond supplies in order to hold their prices (and hence the long-term interests on them) to a set target. Our response is this. As regards the demand side of the story, the two cardinal assumptions made by Godley/Lavoie are that (i) households face a choice of assets as to where to hold their savings, and that (ii) that choice depends not on the yields on assets but on their expected rates of return that are determined by the differences between their prices in the current period and their prices in the next period. In short, household choices are determined by price rather than quantity considerations in the sense defined in this paper. Our argument is that the large institutional investors of today have not the same range of choice as do households. Insurance companies, for example, must at all times hold the majority of their assets in bonds (because of the need to match the maturity profiles of their assets and liabilities) and a substantial proportion of their bond portfolios in government bonds (because of their safety and superior liquidity), which means that all times they need the prices of bonds (that is, their value storage capacity) and the yields on bonds (that is, their source of the monies to be paid out) to remain stable from one period to the next. Turning to the supply side of the story, the key observation here is that if the Treasury varies the supplies of government bonds to the market so as to stabilise their price, this has less to do with stabilising the yield needed by institutional asset managers to carry out their investment function than with smoothing out the interest payments paid by the government on its debt. In sum, Godley/Lavoie's position is essentially that where households make portfolio choices based on price (rate of return) comparisons, the Treasury's task is to reconcile these choices with the constraints on government finances.

8. See for example Wren-Lewis (2007). 
This last observation raises the question as to whether there is a micro-foundational unit of analysis on which can be built a framework that allows for internal and external consistency simultaneously. As individuals are the only ubiquitous constituent elements of a system, the micro unit has to be the representative individual for purposes of internal consistency. But this proposition then leads to the question as to whether this same microfoundational framework can maintain external consistency. Although there is a strong body of opinion that believes this to be an impossibility, ${ }^{9}$ we believe otherwise and point to Marx's concept of commodity as developed in Capital (1867 [1961]) as a solution to the problem. ${ }^{10}$ His use of this concept is unconventional in that it is both more exclusive than is usual - it denotes only those entities that are priced to a market standard - and more inclusive than is usual - it denotes not only the outcomes of human activities but the also the capacities for activity that are subject to pricing standards. In starting with commodities thus defined, Marx starts with individuals, but with the individuals viewed not subjectively but objectively; not as perfectly rational choice maximisers whose aims and objectives are instantaneously matched by some invisible central market force but as reasonably rational agents whose needs are met through decentralised, money-mediated commodity exchanges. ${ }^{11}$ This fact that Marx's commodity world is one where there is all-round interdependence but where that interdependence is only established through bilateral transactions can be used to construct a transactions flow matrix in the postKeynesian style with the difference that the reference points are not sectors but individuals. However, before constructing such a matrix, we first need to ascertain the full range and depth of the commodity principle under capitalism.

A commodity is any entity that is priced against a market standard rather than according to privately negotiated terms. It follows from this definition that, while commodity exchange relations appeared sporadically in most pre-capitalist societies, it is only with the advent of capitalism that such relations are stretched to the point where they become the predominant type. This 'stretching' of the commodity principle to encompass the majority of goods or services produced in a given locality presupposes its simultaneous 'deepening' to encompass the capacity for labour, for only with the transformation of large numbers of individuals into propertyless workers who are forced to rely on the market for their subsistence needs can the market system become an established reality. The emergence of propertyless workers presupposes the simultaneous emergence of firms capable of hiring labour power for a wage. From a purely functional standpoint, firms and workers represent two entirely different groups of agents; however, from a commodity standpoint there is no substantive difference as firms are really nothing other than commodity clusters, amalgamations of labour power and capital capacities. Just as capitalists realise wages when hiring workers and the prices of material inputs when buying or leasing these inputs, so is their own capacity to combine labour and non-labour inputs to produce output subject to the same price realisation process. Monetary and credit systems are old, but the banking sector only really develops under capitalism alongside the development of

9. See for example King (2013).

10. For elaboration of this point, see Lysandrou (1996; 2005).

11. Although the behavioural assumptions here are not very strong, some minimal assumptions are necessary to sustain the very idea of privately assigned prices being made subject to social standards. On this issue we agree with Godley/Lavoie, who reject the assumption that 'agents have perfect information or know perfectly how the macroeconomic system behaves' and argue instead that agents 'display a kind of procedural rationality, sometimes misleadingly called weak rationality or bounded rationality, or more appropriately named reasonable rationality' (Godley/Lavoie 2007 [2012]: 16, authors' emphases). 
firms and wage earners. From a functional standpoint, banks and firms are very different and, indeed, they interconnect precisely because they perform different functions. However, once again, there is no difference from a commodity standpoint inasmuch as banks, along with all other types of private economic organisation, are also clusters consisting of the labour power and capital capacities that are subject to the same pricing process.

The fact that capitalism is a commodity system, and differentiates itself as such from all previous socio-economic systems, means that in principle all human capacities and all the outcomes of these capacities are ultimately subject to the same laws of commodity exchange. If at any stage of capitalism's development there are capacities or outcomes that are not subject to these laws, this does not mean that they are exempt from the commodity principle. All it means is that the particular historical conditions under which they do become subject to the principle are not yet in place. As soon as they fall into place, so does the temporary exemption from the commodity principle come to an end. This is the case with governments. As with private economic organisations, governments viewed from their economic standpoint also consist of two types of human capacity, labour power and the capacity to govern. However, it is only recently, towards the end of the twentieth century, that the government capacity became subject to the commodity principle. Prior to this time, the only developments in government capacity were to do with changes in the scale of its deployment: from the eighteenth century through to the early twentieth century, governments played a small role in domestic economies, while in the middle part of the twentieth century they came to play a very large role. Yet what both periods had in common was the fact that governments could deploy their capacity without reference to any globally sanctioned standards of conduct. Such standards have now come into place, the chief catalyst for this development being the close integration of the global bond markets such that there are now common benchmarks against which government behaviour can be measured.

The pressure on governments to conform to standards and thus avoid or reduce any extra risk premiums being factored into their bond prices has helped to accelerate the ongoing shift away from universal provision of social and welfare services towards more selective forms that concentrate provision on the poorest sections of the population, a shift principally driven by the widening gaps between government expenditure commitments on the one hand and the amounts of tax revenues needed to finance them on the other. This shift directly links in with the transformation of institutional asset management into a mass industry for two reasons: on the one hand, the fact that median income households become more yield-oriented as they are forced to make their own pension and other welfare provision explains the trend move away from bank savings towards capital market investments; while on the other hand, the fact that most households continue to be riskaverse, even though they become more yield-oriented, explains the tendency to invest in capital market instruments via professional intermediaries. As the burden on the institutional asset management function continues to grow in scale, so is there a corresponding continuing increase in the need for investable securities to carry out that function, for although cash, real estate and an assortment of material commodities can go some way towards meeting that need, its bulk has to be met with financial securities largely on account of their superior combination of liquidity and yield properties. It is this increasing institutional need for securities that explains why for the first time in capitalism's history these financial instruments begin to be viewed differently from the way that they are viewed by their issuers, not merely as forms of debt but as commodities whose use value is to serve as portable stores of value.

The upshot of the above discussion is that, in a fully mature economy, there are basically three types of capacity: labour power that earns a wage, capital that earns profit, and 
government that earns tax revenue; which are connected through two basic types of flows: (i) output flows (flows of goods and services that are produced by capacities); and (ii) security flows (flows of claims on capacities and their future output streams). Table 2 shows these linkages in matrix form. The positive and negative values in Table 2 indicate sales (sources of funds) and purchases (uses of funds) respectively; where the summations to zero of the values in the rows indicate the interconnections between different groups of agents, their mutual interdependence for the reproduction of their capacities, the summations to zero of the values in the vertical columns indicate the budget constraints on each group of agents, the limits to what can be absorbed by capacities set by what they produce or by borrowings or by ownership of claims on what other capacities produce. In sum, a commodity transaction flow matrix gives a schematic representation both of 'systemic' consistency, the economic constraints that are binding on all agents' activities, and of 'logical' consistency, the fact that all capacities for activity and all the possible outcomes of those activities are subject to the same law of commodity exchange.

Even if it is accepted that a commodity transactions flow matrix is internally consistent, the question may still be asked as to where, exactly, there is any sign of its external consistency, given that there is no explicit reference either to money or to credit. The answer to this question is that all the essential elements of a monetary economy are subsumed under the assumptions of commodity reductionism. As the connections between individuals are established objectively rather than subjectively, via the commodities they put on sale rather than via any expressions of preferences that are communicated to a central coordinator, it follows that the supply of exogenous money, which is one of the most important services provided by the government capacity, is essential to the whole system of commodity relations: it is through money's function as a measure of value that individuals can assign prices to their capacities and their outputs and it is through money's function as a medium of exchange that privately assigned prices can be realised. Similarly, given that the commodity exchange process is a time-consuming one in which gaps can arise between the acts of price assignment on the one hand and the acts of price realisation on the other, it follows that credit intermediation - the hiring out of money's function as a medium of exchange - constitutes one of the key services performed by the capital capacity. If it is asked why at this stage of the analysis bank loans are not separated out from other services and given their own classification as are debt securities, the answer is that loans are not commodities but credit relations between known counterparties, whereas bonds represent the transformation of credit relations into marketable commodities.

To repeat, commodity reductionism allows for external consistency but on a minimised basis so as to make room for internal consistency. Only when the principle of macroeconomic consistency in both a systemic and a logical sense has been established by concentrating attention on what all groups of agents have in common as commodity sellers is it then advisable to move towards a greater degree of realism by bringing to the

Table 2 'Commodity' transactions flow matrix

\begin{tabular}{lcccc}
\hline & \multicolumn{3}{c}{ Capacities } \\
\cline { 2 - 4 } & Labour & Capital & Government & $\sum$ \\
\hline Goods/services & $+/-$ & $+/-$ & $+/-$ & 0 \\
Securities & $+/-$ & $+/-$ & $+/-$ & 0 \\
$\Delta$ in holdings of goods/services & $+/-$ & $+/-$ & $+/-$ & 0 \\
$\Delta$ in holdings of securities & $+/-$ & $+/-$ & $+/-$ & 0 \\
$\Sigma$ & 0 & 0 & 0 & 0 \\
\hline
\end{tabular}


fore the specific institutional and functional differences that separate groups of agents. The policy implications of this particular order of procedure are outlined below.

\section{THE POLICY-RELEVANT ADVANTAGES OF COMMODITY REDUCTIONISM}

The suggestion that post-Keynesian stock-flow models should take as their point of departure a 'commodity' as opposed to a 'sectoral' transactions flow matrix may raise the objection that, were they to do so, they would end up having little if any policy relevance. This could be because such reductionism may be tantamount to a narrowing down of vision such as would preclude one from seeing how all the different parts of a modern economy fitted together. This possible line of criticism would, in our view, be misplaced. To the contrary, we believe that, were post-Keynesian stock-flow models to begin with a commodity transactions flow matrix to give schematic representation of the structure of a modern economy, they would have more, not less, policy relevance because they would be in a better position to account for new economic phenomena requiring attention on the part of policymakers. In elaborating on this claim, let us again revisit the relation between the accounting and behavioural equations of post-Keynesian stock-flow models.

As previously observed, where the accounting equations are only supposed to describe the systemic constraints on all interlocking activities in a modern economy, it is the subsequent behavioural equations that are supposed to introduce assumptions about the choices and motivations behind economic activities. Put another way, where the accounting equations are meant solely to establish 'consistency' in the stock-flow relations such that there are no 'black holes', it is the behavioural equations that establish 'closure' inasmuch as they model the 'causal' links that bind the different activities together. To quote G-L: 'While it is crucial to have coherent accounting and stock-flow consistency, the behaviour of the model and its results depend as well on the closure and causality of the model, that is, on the behavioural equations that will be associated with the accounting equations' (2007 [2012]: 15). This passage contains a concise summary of what should be the distinction between the accounting and behavioural dimensions of stock-flow macro models, but what is curious is that, having made this distinction, $\mathrm{G}-\mathrm{L}$ then proceed in a way that flouts it.

In their opening set of accounting matrices, there is far too much going on. Five sectors are introduced, each performing a distinct function: households engaging in consumption, firms in production, banks in credit intermediation, and so on. Now any discussion of the goals and motivations of different groups of agents is supposed to wait until the behavioural equations are introduced, but as these goals and motivations cannot be separated out from the specific functions performed by each sector, it follows that by introducing the sectoral differences in the accounting equations these in effect smuggle in behavioural assumptions through the back door. The problem here is that if elements of causality and closure are brought into a methodology that initially is only supposed to establish consistency, the end result is more likely inconsistency and an absence of closure in the sense that certain important behavioural assumptions go missing, as is notably the case in regard to institutional investors. The point is that the distinguishing characteristics of households, firms and banks in the nineteenth or twentieth centuries are not all that different from the characteristics that these sectors have in the present, which means that to keep attention consistently focused on these sectors and on the distinct functions that they perform runs the risk of missing out on the emergence of any new economic phenomena. 
Now take commodity reductionism. We have said that each successive period of capitalism exhibits differences from each previous one in that aspects of human economic activities not previously subject to socially sanctioned rules of pricing now become subject to such rules. What this means is that if the evolution of an economic system over time is viewed through the evolution of the commodity exchanges that link its different sectors together, rather than through the evolution of these sectors and their functions as such, it becomes easier to identify what is historically new about that system at any given point in time. Thus another advantage of commodity reductionism is that it enables one not only to see across space (to identify the generality of the commodity principle) but also across time (to track the unfolding development of the commodity principle). This is the case with securities. Firms, the main issuer of securities, have never and can never see them as commodities but only as means of financing the production of commodities. It is different with institutional investors. Following the increase in the scale of asset management and a corresponding increase in the need for investables, institutional investors now see firms and governments as 'dual' commodity providers, supplying not only the goods or services needed by households for consumption purposes but also the stores of value needed by themselves for portfolio purposes.

It is here that we come to the question of policy, because just as the behavioural equations have to be amended to accommodate the changes in the asset management industry and in the securities markets that this industry relies upon, so must they also be amended to accommodate the need for policy intervention in these markets. As stated, the functional differences separating organisations should be brought to the fore at the point where the behavioural equations are introduced because these differences have a direct bearing on the goals and objectives that motivate agents. Thus the differences in the capital capacity as deployed in firms and banks have a bearing on the different ways in which these organisations generate profit. In the government capacity, the main functional division is between the government sector, whose primary role is to provide goods and services that are either not privately provided or are provided on terms and in quantities that only partly meet societal needs, and the central bank whose primary role is to control the supply of outside money - money that, because of government backing, receives public trust in its key functions. This difference in service provision extends to the difference in stabilisation policies that must be pursued in market economies that are prone to sharp swings in economic activity, with the government being responsible for fiscal policy and the central bank for monetary policy.

All this is familiar in post-Keynesian stock-flow models, but what is missing is the premise that the government now has to pursue the same kind of stabilisation policy in the capital markets as they do in the labour and product markets, adjusting the supplies of their own debt securities to correct for any substantial quantitative mismatches between the aggregate demands and supplies of these securities. The point is that not only do all large investors such as insurance companies and pension funds hold a mixture of equity and bond portfolios, but also that all institutionally held bond portfolios contain substantial amounts of government bonds at their core. This emergence of government bonds as the operational centre of institutional bond portfolios, and hence of the bond markets where institutional investors predominate, means that there is now a direct parallel between the government and the central bank, in that, just as the latter must (at times of a liquidity shortage in the banking sector) supply extra liquidity by acting as 'lender of last resort', so must the former (at times of a shortfall in the supplies of investable securities relative to investors' demands) supply extra securities by acting as 'borrower of last resort'.

This observation has particular resonance in the current, post-crisis period because the 'search for yield' phenomenon that helped to precipitate the financial crisis has again 
reared its head. The reason is that while the crisis has had a prolonged dampening effect on global supplies of private sector securities, it has not had a similar effect on the volume of global demand for securities exercised by institutional and other investors. Thus if governments that have both the economic and institutional means of issuing more debt securities in the amounts needed to close the gap between global demand and supply prove reluctant to do so, there is a real danger that amongst the alternative means used by investors to satisfy their need for yield will be those who can pose an eventual threat to economic stability. Supplies of government bonds have of course increased in the postcrisis period in line with fiscal expansion aimed at containing the fall-out of the crisis, but the fears and paranoias surrounding the growth of government debt have meant that the supply increases will not only be capped but in many key cases reversed, as some governments switch from fiscal expansion to fiscal consolidation and other austerity measures. Mainstream macro models bear a responsibility here, for the methodological individualism responsible for giving these models their inner coherence is also responsible for making them a formidable obstacle to the type of interventionist policies that are required in the post-crisis era.

The conclusion from the above discussion is that post-Keynesian stock-flow macro models are well positioned to strengthen their policy credentials at the expense of the current mainstream models. Post-Keynesian models as currently constructed go halfway towards filling in the policy gaps. However, if they are to go all the way, they need to integrate the securities markets into their framework in a way that shows these markets as operating to the same demand-led quantity adjustment processes as do the real markets and thus as requiring, periodically, the same type of interventionist stabilisation policy as is applied in the real markets. ${ }^{12}$ In the final analysis, governments will only persist with bondfinanced expansionary fiscal policies as long as economic conditions remain depressed when the fears surrounding government debt levels are dispelled, and this will not happen unless securities markets are fully integrated into a macroeconomic policy framework.

\section{CONCLUSION}

The financial crisis has tarnished the reputation of mainstream macro models in the eyes of policy-makers not only because they did not predict the timing or the scale of the crisis but also because they did not predict the direction from which the crisis would come. Financial crises in these models are supposed to result from exogenous shocks, but the sub-prime crisis was most emphatically the result of an endogenous shock. It did not happen because of any sudden shifts in technology or because of any sudden disruption to supplies of natural resources. It happened because of attempts on the part of the US financial sector, which is at the very heart of the world's financial system, to escape the limits of securitisation imposed by the normal rules of commodity exchange. Given that official confidence in mainstream models has been shaken by the crisis, there is a realistic chance that alternative models, such as those of the post-Keynesian stock-flow variety, will be taken more seriously by policy-makers than has been the case in the past. However, for these models to be able to capitalise on this opportunity, they first need to win more support from within the economics profession; and this will only happen if the profession is convinced that the alternative macro models contending for policy attention are not only externally realistic but also internally coherent. This paper has suggested a possible way of achieving this objective.

12. For further elaboration of this argument, see Lysandrou (2013). 


\section{REFERENCES}

Bandholz, H., Clostermann, J., Seitz, F. (2009): Explaining the US bond yield conundrum, in: Applied Financial Economics, 19(7), 539-550.

Bernanke, B.S., Bertaut, C., Pounder DeMarco, L., Kamin, S. (2011): International capital flows and the returns to safe assets in the United States: 2003-2007, in: Banque de France Financial Stability Review, 15, 13-26.

Caballero, R.J. (2010): The 'other' imbalance and the financial crisis, NBER Working Paper No. 15636.

Coeure, B. (2012): Which models do we need in times of crisis?, European Central Bank, October.

Godley, W., Lavoie, M. (2006): Prolegomena to realistic monetary macroeconomics: a theory of intelligible sequences, The Levy Economics Institute, Working paper No. 441.

Godley, W., Lavoie, M. (2007 [2012]): Monetary Economics, 2nd edn, Basingstoke, UK: Palgrave Macmillan.

Goda, T., Lysandrou, P. (2013): The contribution of wealth concentration to the subprime crisis: a quantitative estimation, in: Cambridge Journal of Economics, forthcoming.

Goda, T., Lysandrou, P., Stewart, C. (2013): The contribution of US bond demand to the US bond yield conundrum of 2004 to 2007: an empirical investigation, in: Journal of International Finance and Financial Markets, 27(C), 113-136.

Grahl, J., Lysandrou, P. (2006): Capital market trading volume: an overview and some preliminary conclusions, in: Cambridge Journal of Economics, 30(6), 955-979.

King, J.E. (2013): The Microfoundations Delusion: Metaphor and Dogma in the History of Macroeconomics, Cheltenham, UK and Northampton, MA: Edward Elgar.

Kocherlakota, N. (2010): Modern macroeconomic models as tools for economic policy, Minneapolis Federal Reserve, 2009 Annual Report Essay.

Lysandrou, P. (1996): Methodological dualism and the microfoundations of Marx's economic theory, in: Cambridge Journal of Economics, 20(5), 565-584.

Lysandrou, P. (2005): Globalisation as commodification, in: Cambridge Journal of Economics, 29(5), 769-797.

Lysandrou, P. (2011): Inequality as one of the root causes of the financial crisis: a suggested interpretation, in: Economy and Society, 40(3), 323-344.

Lysandrou, P. (2013): Debt intolerance and the $90 \%$ debt threshold: two impossibility theorems, in: Economy and Society, 42(4), 521-542.

Lysandrou, P., Stoyanova, D. (2007): The anachronism of the voice exit paradigm: institutional investors and UK corporate governance, in: Corporate Governance: International Review, 15(6), 1070-1078.

Marx, Karl (1867 [1961]): Capital, London: Lawrence and Wishart.

Van Treeck, T. (2009): A synthetic, stock-flow consistent macroeconomic model of financialisation, in: Cambridge Journal of Economics, 33(3), 467-493.

Warnock, F.E., Cacdac Warnock, V. (2009): International capital flows and U.S. interest rates, in: Journal of International Money and Finance, 28, 903-919.

Wren-Lewis, S. (2007): Are there dangers in the microfoundations consensus?, in: Arestis, P. (ed.), Is There a New Consensus in Macroeconomics?, Basingstoke, UK: Palgrave Macmillan, 43-60. 